\title{
APLICAÇÃO DE VETORES À COMPUTAÇÃO GRÁFICA: UM ESTUDO DE CASO
}

\author{
APPLICATION OF VECTORS TO COMPUTER GRAPHICS: A CASE \\ STUDY
}

\author{
Francisco Alves dos Santos ${ }^{1}$ \\ Alexandre Ramalho Silva²
}

\begin{abstract}
RESUMO: O presente trabalho reporta acerca da realização e das conclusões obtidas após uma oficina sobre vetores aplicados à computação gráfica. A mesma foi desenvolvida em uma turma do curso de licenciatura em matemática de uma instituição de ensino da rede federal da cidade de São Raimundo Nonato-PI, que já havia cursado a disciplina de geometria analítica. Na oficina, foi mostrada a aplicação de vetores para simular movimentos de objetos em um ambiente virtual, programa processing 3.3.5 (gratuito para download). Os objetivos dessa pesquisa são investigar a satisfação e o desempenho dos discentes durante a aplicação da oficina e verificar qual melhoria no aprendizado dos mesmos, no estudo da geometria analítica. A metodologia usada traz em sua composição, uma avaliação diagnóstica, uma avaliação intermediária, uma intervenção e um questionário final, com perguntas abertas com intuito de verificar a compreensão da aplicação de vetores em computação gráfica por parte dos alunos, bem como se os mesmos concordam que a contextualização é importante no processo de ensino-aprendizagem. Pode-se afirmar que os alunos compreenderam como as operações com vetores são aplicadas na programação, em especial em movimentos de objetos em ambientes virtuais e demonstraram interesse em aprofundar seus conhecimentos em geometria analítica. Concluindo, podemos afirmar que a contextualização dos conteúdos matemáticos e sua aplicação, por parte do docente, favorecem, considerável e positivamente, o processo ensino-aprendizagem.
\end{abstract}

PALAVRAS-CHAVE: Ensino da matemática. Ambiente virtual. Programação.

ABSTRACT: This work reports about the realisation and obtained conclusions after aworkshop on vectors applied to computer graphics. The workshop was developed for a group of mathematics undergraduate students from a federal educational in São Raimundo Nonato city (PI). These students had already studied analytic geometry. In the workshop, it was shown the application of vectors to simulate object's movements in a virtual environment from program processing 3.3.5 (free to download). The objectives of this research are investigate students' satisfaction, analyse their performance during the application of the workshop and verify the improvement in their learning in the studyof analytical geometry. The methodology is based on a diagnostic evaluation, an intermediate evaluation, and a final questionnaire, with objetive questions in order to verify the students' understanding of vectors application in computer graphics, as well as if they agree that the contextualization is important in the teaching-learning process. It can be said that the students obtained a satisfactory understanding of the role that theoperations with vectors perform in the programming, in what refers to movements to objects in virtual environments and showed interest in deepening their knowledge in analytical geometry. In conclusion, we can affirm that the contextualization of the mathematical contents and their application, by the teacher, favor, considerably and positively, the teaching-learning process.

KEYWORDS: Mathematics Teaching. Virtual Environment. Programming.

\footnotetext{
${ }^{1}$ Instituto Federal do Piauí. E-mail: fas@ifpi.edu.br

https://orcid.org/0000-0001-6386-1498

2 Universidade Federal do Vale do São Francisco. E-mail: alexrama.univasf@gmail.com

(i) https://orcid.org/0000-0002-0635-4171

- Informações completas da obra no final do artigo
} 


\section{Introdução}

O estudo sobre vetores ou grandezas vetoriais, é introduzido no ensino por meio das disciplinas de exatas desde o início do ensino médio, quando se estuda, na física, sobre velocidade, aceleração e forças, por exemplo. Para aqueles que optam por um curso superior na área de exatas, tais como engenharias, licenciaturas ou bacharelados em matemática ou física, esse estudo é mais aprofundado nas disciplinas de geometria analítica álgebra linear e, importantes componentes curriculares desses cursos.

Esse trabalho relata os resultados de uma pesquisa sobre aplicação de vetores geométricos no campo da computação gráfica. É uma introdução à lógica de programação usada nos jogos de computadores para dar movimentos a objetos em um ambiente virtual, por meio de comandos que envolvem operações com vetores, entre outras.

Foi ao participar de um minicurso sobre a aplicação de vetores geométricos em jogos de computadores em um evento de matemática (III Encomat), na instituição da qual sou docente, que surgiu a ideia de trabalhar, em forma de minicurso, com os alunos da mesma instituição de ensino, que já haviam cursado a disciplina geometria analítica, a aplicação de tal componente matemático, na computação gráfica. Isso se deve à busca por métodos de ensino que sejam capazes de despertar no discente, o interesse pelo aprender matemática, e tornam a aprendizagem mais significativa.

As experiências adquiridas como professor de matemática nos ensinos fundamental, médio e superior, desde 2002 até a presente data, me permitiram observar que muitas metodologias utilizadas no ensino da matemática são ineficazes e levam a um distanciamento, por parte do aluno, da disciplina em questão. Para dar fim, ou diminuir às consequências desse "mito" de que aprender matemática é para poucos, vem se pensando, ao longo dos anos, em métodos que façam com que o aluno passe de sujeito passivo a sujeito ativo no processo ensino-aprendizagem.

O aluno será capaz de aprender, quando for capaz de construir seu conhecimento, assimilando e associando aquilo que aprende com o mundo à sua volta, com seu cotidiano. Não obstante, trabalhar a aplicação da matemática em outros componentes curriculares de maneira interdisciplinar, mostra ao aluno que essa disciplina tem um vasto campo de aplicações práticas. Mostra-se ainda que a matemática enquanto conhecimento, ultrapassa o campo da abstração, contrariando o que muitos discentes julgam acerca disso, por não 
conhecerem a relação entre a matemática e as outras áreas do conhecimento. Em síntese, mostrar essa relação é uma maneira de dinamizar o ensino, e isso colabora com o aprendizado do aluno. Os PCNs acrescentam que

O professor, considerando a multiplicidade de conhecimentos em jogo nas diferentes situações, pode tomar decisões a respeito de suas intervenções e da maneira como tratará os temas, de forma a propiciar aos alunos uma abordagem mais significativa e contextualizada. (BRASIL 1997, p. 44).

O presente trabalho traz como proposta, mostrar a aplicação de vetores geométricos na computação gráfica. Em suma, de forma não aprofundada, é trabalhada a aplicação de vetores para dar movimento a objetos em um ambiente virtual. Para isso, se faz necessário conhecer algumas propriedades dos vetores e trabalhar algumas operações que envolvem os mesmos.

Quando comecei a ministrar aulas de matemática na instituição de ensino da qual hoje sou professor, no ensino superior, pude ver o quão grande é a deficiência dos discentes em conteúdos matemáticos básicos. Pude também presenciar o desestímulo, por parte de alguns discentes, em estudar algumas disciplinas da grade curricular, por não conhecerem sua aplicação prática, ou que relação há entre os conteúdos estudados e o seu dia a dia.

O panorama atual requer propostas desafiadoras e um tanto atrativas para os alunos do Ensinos Fundamental, do Médio e do ensino superior. O trabalho escolar deve ser pensado e elaborado de acordo com a necessidade do corpo discente, tendo em vista alargar o seu leque de conhecimento da disciplina matemática por meio da sua aplicação prática, pois não é prazeroso aprender aquilo que não tem "utilidade". O aluno necessita conhecer a profundidade daquilo que está aprendendo, e saber em que momento da vida esse conhecimento Ihe será útil. Ele precisa saber que o aprender matemática não consiste em memorização de regras e fórmulas que serão usados em determinados momentos e depois serão esquecidos. A esse respeito os PCNs acrescentam que:

Os Conteúdos do ensino correspondem aos conhecimentos e valores sociais acumulados pelas gerações passadas como verdades acabadas, e, embora a escola vise à preparação para a vida, não busca estabelecer relação entre os conteúdos que se ensinam e os interesses dos alunos, tampouco entre esses e os problemas reais que afetam a sociedade. (BRASIL, 1997, p. 27) 
É vasto o campo de aplicação dos conhecimentos matemáticos adquiridos em sala de aula, mas o aluno "não" sabe disso, pois na sala de aula, seu aprendizado é limitado, priorizando algebrismos, memorização e o trabalho descontextualizado.

Para despertar o interesse no aluno pelo aprender matemático, é necessário mostrar ao mesmo que a referida disciplina tem aplicação prática, e não subsiste apenas de teoria, problematizando os conteúdos adequadamente e mostrando suas áreas de aplicação. Torres acrescenta:

\begin{abstract}
Assim, surge à necessidade de favorecer um ensino que leve o educando a problematizar os mais variados conceitos abordados na referida disciplina escolar. O homem como ser social e integrante de uma cultura necessita do conhecimento matemático na sua relação interpessoal, muitas vezes não sendo perceptível a sua utilização. No entanto, ele o utiliza assim como utiliza a sua língua materna. (TORRES 2016, p. 2)
\end{abstract}

Assim, faz-se necessário avançar do campo teórico para o prático, para mostrar aos discentes alguns ramos da aplicação dos conteúdos ministrados em sala de aula.

Diante de tais discussões surge a necessidade de se buscar ensinar a matemática de modo que mesma venha a favorecer ao aluno a aplicar seus conceitos, seja em conexão com outras áreas como a física, a geografia, a computação gráfica; seja no cotidiano. Segundo Menezes:

À medida que se defende a necessidade da utilização da matemática no
cotidiano, inevitavelmente deve-se perceber que existem sujeitos envolvidos no
processo de ensino e aprendizagem, de um lado temos o sujeito que ensina ou
media e do outro o que aprende ou que constrói o conhecimento junto com o
sujeito mediador. (MENEZES, 2016 apud CONCEIÇÃO et al., 2015)

Alguns professores de matemática ainda estão presos a um modelo de ensino que não promove no aluno a mobilização da aprendizagem e nem a motivação para perceber que essa disciplina está presente em suas relações sociais. Assim, esse componente curricular torna-se, muitas vezes, distante da realidade do aluno. Isso está relacionado à maneira como ela é trabalhada em sala de aula. Além disso, a ausência de relacionamento da teoria com a prática no ensino da disciplina em questão, associada à sua não aplicação no cotidiano do discente, leva o aluno a não despertar em si o interesse pela disciplina.

O professor conduz a interação de diferentes tipos de alunos que podem pertencer à culturas diversas, e na da sala de aula tais alunos discordam entre si em muita coisa, mudam de opinião, e cada um deles possui o seu próprio tempo de aprendizagem. Eis o 
primeiro problema que o professor encontra dentro da sala de aula: como nivelar o ensino, tendo tantas disparidades entre os alunos sob sua responsabilidade.

Em se tratando do ensino superior, tais instituições de ensino, que se caracterizam por instituições que produzem conhecimentos, e que estimulam a formação crítica do discente, devem ter um corpo docente que faça uso de metodologias diversas, aperfeiçoando a prática docente pedagógica. No tocante ao ensino da matemática nessas instituições de ensino, tais conteúdos devem ser abordados mostrando a relação dos mesmos com o cotidiano do aluno; ou, onde, em que, e como o aluno fará uso de tais conhecimentos. Para Masola e Allevato (2016)

Com o pensar voltado para a formação prospectiva e tentando antecipar os desafios que aguardam os egressos no futuro, do qual ainda não se conhece todo o contorno, busca-se uma aprendizagem ativa e problematizadora voltada para a autonomia intelectual, apoiada em formas criativas e estimulantes para o processo de ensino, formando um profissional comprometido com a curiosidade epistemológica e com a resolução de problemas da realidade cotidiana (MASOLA e ALLEVATO, 2016, p. 2).

O ensino, para o professor, é um desafio que ele necessita superar. Sua prática educacional deve adaptar-se ao exigido para cada situação, em particular. A prática do docente deve ser pensada de tal maneira que o professor auxilie na transformação da instituição e suas tradições.

Não é uma tarefa difícil, mas trabalhar a aplicação dos conteúdos matemáticos para alunos do curso superior exige do docente uma preparação mais profunda do que o convencional. É necessário que o professor se adapte (na maioria das vezes) ao uso de tecnologias que permitem simular as aplicações dos conteúdos matemáticos a outras áreas do conhecimento, ou prever certos acontecimentos por meio da criação de gráficos em regressão linear ou polinomial, que são criados por meio de algoritmos e cálculos matemáticos em uma plataforma de programação usando uma linguagem de programação específica, ou mesmo para simular fenômenos do mundo real dentro de um ambiente virtual (esse é o objeto dessa pesquisa).

Há, entre os componentes curriculares do ensino da matemática no ensino superior, algumas disciplinas de cujo ensino se distancia muito da realidade do aluno. Uma das disciplinas que mostra-se bastante distante de sua aplicação prática quando é lecionada, é a geometria analítica. Os vetores, por sua vez, apesar de terem aplicações em uma infinidade de campos, na maior parte das vezes é trabalhado fora do contexto. 


\section{ENSIN@UFMS 2021}

ISSN 2525-7056

Considerando essas premissas, elaboramos uma oficina que mostra a aplicação de operações entre vetores à computação gráfica.

Durante a aplicação desse projeto, os estudantes envolvidos foram submetidos à avaliações e questionários, que foram usadas para coleta dos dados, e que auxiliaram no resultado pesquisa. O objetivo geral deste trabalho é analisar o desempenho e satisfação do aluno em uma oficina em que conceitos básicos sobre vetores e geometria analítica são trabalhados usando um software de computador, onde são simulados movimentos de objetos em ambientes virtuais por meio de operações com vetores.

São objetivos específicos: investigar o desempenho dos alunos durante a realização da oficina supra citada, acerca da aplicação de vetores, quando usados para introduzir movimentos a objetos dentro de um ambiente virtual e; verificar qual a melhoria no aprendizado do aluno, em relação aos conceitos de geometria analítica após a realização da oficina.

A presente pesquisa traz em sua composição, além dessa introdução, um referencial teórico que a embasa, por meio da visão de alguns autores, e traz vários exemplos sobre o uso dos vetores geométricos por meio das operações básicas de adição, subtração, normalização e multiplicação de um vetor por escalar, seguidos de explicações que visam simplificar a compreensão do leitor quanto ao uso dos vetores para tal fim.

Na sequência, trazemos a metodologia da pesquisa de forma detalhada, mostrando os passos de desenvolvimento desse trabalho.

Em seguida os resultados e as discussões baseados na coleta dos dados obtidos durante o desenvolvimento do projeto; e

Por fim, são apresentadas algumas considerações finais, que buscam comparar a questão norteadora, com os resultados obtidos e analisados na disquisição.

\section{Referencial teórico}

Neste tópico do trabalho, será apresentado o referencial teórico desta pesquisa, trazendo a visão de alguns autores que embasaram o desenvolvimento da mesma, e exemplos que tratam do uso de vetores para dar movimentos a objetos dentro de um ambiente virtual. 


\section{Dificuldades no processo ensino-aprendizagem, como saná- las?}

Levando em consideração o crescente desinteresse dos alunos das escolas do tempo presente, e os fatores que levam a isso, vem se pensando em métodos e técnicas que despertem neles o prazer pela aprendizagem da matemática. Essa falta de interesse, por parte dos alunos, associada à falta de métodos dinâmicos no ensino da disciplina em questão, tem levado à deficiência no ensino dessa disciplina e tem criado cada vez mais, lacunas nesse processo tão importante na relação aluno- escola-professor.

De acordo com os Parâmetros Curriculares Nacionais - PCNs (BRASIL, 1997,p. 21) "mesmo os alunos que conseguem completar os nove anos do ensino fundamental acabam dispondo de menos conhecimento do que se espera de quem concluiu a escolaridade obrigatória". Os PCNs (BRASIL 1997, p. 10) definem escolaridade obrigatória como sendo os nove anos do ensino fundamental.

Ao final da escolaridade obrigatória, os alunos aprenderam pouco, e muitas vezes o que aprenderam não facilita sua inserção e atuação na sociedade. Dentre outras deficiências do processo de ensino e aprendizagem, são relevantes o desinteresse geral pelo trabalho escolar, a motivação dos alunos centrada apenas na obtenção de notas e na promoção, o esquecimento precoce dos conteúdos estudados e os problemas de indisciplina. Pensando em mudar essa visão, são muitas as maneiras de se dinamizar o ensino da Matemática, como por exemplo, a utilização de jogos como ferramenta de auxílio ao ensino da disciplina em questão, e sua relação com o dia a dia do aluno.

A matemática mantém grande relação com a área da computação. A própria linguagem de computadores (binária) é um exemplo disso. Por trás daquilo que aparece na tela do computador temos pura aplicação matemática. Ressaltamos que o ensino de linguagem de programação é importante, e auxilia no aprendizado do aluno. Segundo Reif (2017, p. 13)

Nos dias de hoje, aprender a programar é um diferencial comparado ao que foi
aprender inglês há alguns anos, e deveria ser tão importante quanto ler ou escrever.
Essa importância não se limita apenas às oportunidades de trabalho, ela possibilita
ver o mundo de novas maneiras. (REIF, 2017, p. 13)

Devido a sua imensa importância e à falta de profissionais com habilidades em programação, muitos países perceberam que este aprendizado deve ser incorporado ao currículo das crianças ainda na fase escolar. Dessa maneira, desde cedo elas têm acesso 
à linguagem de programação, que auxilia no aprendizado de outras disciplinas assim como o desenvolve diversas habilidades pessoais como raciocínio lógico, trabalho em equipe, tomada de decisões e criatividade.

Para Reif (2017), inserção da linguagem de programação por meio da aplicação na matemática, reforça os ideais da prevalência de uma nova postura metodológica em detrimento da postura tradicional de ensino, ainda dominante no ambiente escolar. É importante introduzir nas escolas metodologias que possibilitem o aprendizado do aluno. Técnicas voltadas para a aplicação matemática contribuem para o aprendizado da mesma.

Na seção seguinte, será mostrada a grande importância de se mostrar como se dá aplicação dos vetores de forma a dar movimentos a seres no ambiente virtual. Comandos gerados por meio de linguagens de programação Java permitem aplicar esse tão importante componente matemático na área da computação de modo a dar movimento a objetos na tela do computador.

\section{Vetores: breve contexto histórico}

Esse ente matemático, muito importante na física e em outras áreas, foi concebido, da forma como se conhece hoje, através de uma história muito longa. O registro mais antigo que se tem, conforme MARTINS (2015) remontam à Grécia Antiga. Ainda conforme esse autor, "trata-se da lei do paralelogramo para a adição de vetores que pode ter aparecido em um trabalho de Aristóteles que foi perdido, e que encontra-se na Mecânica de Herão de Alexandria“. Ainda conforma MARTINS (2015), esses cálculos aparecem no primeiro corolário do Philosophiae Naturalis Principia Mathematica (1687), escrito por Isaac Newton.

No século XIX, a necessidade de representar um número complexo fez com que vetores fossem usados para representá-lo geometricamente. Conforme ROSA (1998):

Historicamente os Números Complexos surgiram quando Bombelli, ao tentar resolver uma equação do 30 grau, usando a fórmula de Cardano-Tartaglia, deparase com a raiz quadrada de um número negativo. Como ele sabia a priori que esta equação tinha solução, é levado a pensar que existe a raiz quadrada de um número negativo e começa a operar com essas raízes, não as considerando como números, mas sim como representações [...] A ideia é propor aos alunos que resolvam uma equação do terceiro grau, pelo método de Cardano-Tartaglia. Ao resolvê-la eles poderão se deparar com a raiz quadrada de um número negativo [...]. (ROSA, 1998, p. 114). 
A descoberta da fórmula de Cardano-Tartaglia, que mostrava números complexos associados a equações cujas soluções reais eram conhecidas fez com que o estudo dos números complexos fossem alavancados. Conforme SANTOS (2018), no século XIX:

[...] matemáticos como Caspar Wessel (matemático dinamarquês-norueguês, 17451818), Jean Robert Argand (um livreiro e matemático amador francês, nascido na suíça, 1768 - 1822), Carl Friedrich Gauss (matemático, astrônomo e físico alemão que contribuiu muito em diversas áreas da ciência, dentre elas a teoria dos números, estatística, análise matemática, geometria diferencial, Geodésia, geofísica, eletrostática, astronomia e óptica, 1777 - 1855), entre outros, conceberam números complexos como pontos no plano bidimensional, isto é, como vetores bidimensionais (SANTOS, 2018, p. 21).

Buscando criar uma ponte entre a Álgebra e a Geometria e ratificar as teorias que envolvem o conjunto dos números complexos, matemáticos dos séculos XVII e XVIII, debrussaram-se na tentativa de desenvolver um sistema de representação geométrica para estes números. Originando com isso, os métodos da Análise Vetorial. Porém, até o final do século XVIII, não havia nenhuma teoria ou conjunto de regras bem definidas que pudessem ser chamadas de Álgebra Vetorial, pois o estudo sistemático e o uso de vetores foram fenômenos do século XIX e início do século XX.

August Ferdinand Möbius publicou, em 1827, o livro The Barycentric Calculus, no qual introduziu diretamente segmentos de reta que eram representados por letras do alfabeto; representação de vetores, mas não no nome.

Um trabalho foi publicado por Giusto Bellavits (matemático italiano, 1803-1880) sobre Geometria, em 1832, onde ele abordou a noção de vetor de maneira explícita. Os elementos básicos da sua obra são os segmentos de reta. Dados dois pontos $A$ e $B$ do plano, os segmentos $A B$ e $B A$, de extremidades $A$ e $B$, foram considerados por Bellavits elementos distintos. Essa convenção foi admitida por ele devido ao fato de que o segmento de reta delimitado pelos pontos $A$ e $B$ pode ser encontrado de duas maneiras diferentes: partindo de $A$ para $B$, ou partindo de $B$ para $A$. A classificação dos segmentos feita por Giusto, deu-se através da relação de equipolência que, por sua vez, originou a noção de vetor.

A aplicação dos vetores geométricos na computação gráfica, usados para darem movimentos aos seres em um ambiente virtual e fazer algumas simulações. A computação gráfica é a área da computação destinada à geração de imagens em geral, em forma de representação de dados e informações, ou de fenômenos do mundo real. 
A aplicação dos vetores geométricos dentro desse campo de conhecimento se dá, por meio de operações que permitem simular movimentos de objetos dentro do ambiente virtual. Por meio dessas operações, pode-se simular, por exemplo, ainda sem o uso de vetores, um objeto circulando dentro do ambiente virtual refletindo seu movimento nas bordas da telinha.

Fazendo uso das operações com vetores, podem-se simular esses movimentos imprimindo ao objeto, velocidade por meios e comandos específicos usando operações com vetores que permitem a atualização da posição do vetor a cada execução dos comandos. Pode-se fixar a magnitude e calcular a norma de um vetor por meio da subtração de vetores.

Essas operações permitem também imprimir uma aceleração ao objeto por meio da adição de vetores; permitem fazer o objeto seguir o mouse; permitem aplicar gravidade (única ou randômica) a um ou mais objetos; permitem modelar uma força aplicada a um objeto; permitem aplicar atrito ao movimento de um objeto, entre muitas outras simulações, apenas por meio das operações com vetores.

\section{Metodologia}

Os métodos de investigação utilizados na presente pesquisa foram o quantitativo e qualitativo, para Prodanov e Freitas(2013), este último tem como raízes filosóficas a fenomenologia e a interação simbólica, e o método qualitativo tem o método indutivo como método de análise, dos quais as características são descritas ou explicadas, ou seja, se foca no caráter subjetivo do objeto analisado em questão, estudando as suas particularidades e experiências individuais.

$\mathrm{Na}$ pesquisa qualitativa o conjunto inicial de categorias pode ser reexaminado e modificado sucessivas vezes, com vistas a obter ideias e resultados mais abrangentes e significativos.

A pesquisa quantitativa considera que tudo pode ser quantificável, o que significa traduzir em números opiniões e informações para classificá-las e analisá-las. Tem como raízes filosóficas o positivismo, o empiricismo e o lógico; e como coleta de dados, instrumentos manipulados como escala, testes, questionários e etc. Seu método de análise é o dedutivo, por meio do método estatístico. Marconi e Lakato acrescentam que 
As técnicas rigorosas de amostragem têm o objetivo de possibilitar a generalização das descobertas a que se chega pela experiência. Por sua vez, para que possam ser descritas quantitativamente, as variáveis relevantes são especificadas. Os diversos tipos de estudos experimentais podem ser desenvolvidos tanto "em campo", ou seja, no ambiente natural, quanto em laboratório, onde o ambiente é rigorosamente controlado. (MARCONI e LAKATO, 2003, p. 188)

A escolha dos métodos quantitativos e qualitativos aplicados a este trabalho, se devem; primeiro, ao fato de se necessitar quantificar (por meio dos gráficos) os dados coletados pelos questionários fechados que tem como objetivo trabalhar as operações com vetores (muito citadas anteriormente) e; julgar a eficácia de métodos de ensino voltados a trabalhar a aplicação de conteúdos matemáticos por meio da contextualização dos mesmos, e sua relação com outras áreas.

A ordem de execução do presente trabalho seguiu uma sequência desenvolvida em quatro etapas, a saber:

1. Avaliação diagnóstica, que permitiu fazer uma análise prévia sobre o conhecimento dos alunos acerca do conteúdo vetores;

2. Construção de exemplos que envolveram a aplicação de vetores para simular movimentos de objetos em ambientes virtuais;

3. Avaliação intermediária simulando movimentos de objetos por meio da manipulação dos comandos;

4. Avaliação final, baseada em um questionário para julgar a eficácia do desenvolvimento desse trabalho e sua importância para o aprendizado do aluno, e sua contribuição para o ensino do estudo dos vetores.

O presente trabalho teve como público alguns discentes do curso de licenciatura em matemática de uma instituição de ensino superior da cidade de São Raimundo Nonato-PI (os que já haviam cursado a disciplina geometria analítica) e foi realizado em dois encontros de $4 \mathrm{~h}$, cada.

\section{Resultados e discussões}

Durante o primeiro encontro foi, inicialmente, realizada uma avaliação diagnóstica com questões voltadas a operações com vetores (essas operações se fazem necessárias para que o aluno entenda como programar esses elementos de modo a alcançar os objetivos deste trabalho). Essa avaliação também buscou identificar se aluno conhece alguma aplicação prática de vetores, se considera relevante esse estudo no curso de 


\section{ENSIN@UFMS 2021}

ISSN 2525-7056

licenciatura em matemática e se durante o curso, na disciplina geometria analítica, foi exposto a ele onde seriam aplicados os conhecimentos adquiridos, assim como a relação do conteúdo com outras áreas do conhecimento.

A pesquisa mostrou, inicialmente, que maioria dos discentes não conhecia nenhuma aplicação prática dos vetores. Consideram relevante o estudo do conteúdo em questão, mas não souberam justificar o porquê. A maioria também relatou que durante o período em que cursaram a disciplina geometria analítica não foi mostrada nenhuma aplicação prática dos vetores ou sua relação com outras áreas. Os dados estão registrados nos gráficos a seguir.

As respostas dadas pelos alunos permitiram direcionar o estudo dos vetores por meio de exemplos voltados a sanar as dúvidas iniciais que os mesmos tinham acerca de algumas operações e suas representações geométricas.

O Gráfico 1 tabula os dados da pesquisa referentes ao questionário aberto feito com os discentes. Dos dados obtidos, pode-se constatar que a maioria não conhecia nenhum ramo da aplicação dos vetores geométricos, isso se deve ao fato dos mesmos terem sido submetidos a metodologias de ensino que não lhes permitiram associar a teoria com a prática. Um aluno relatou conhecer a aplicação dos vetores no campo da computação gráfica, por ter participado de um minicurso onde foi abordada tal aplicação, mas durante o curso de licenciatura em matemática, quando cursou a disciplina geometria analítica, não viu nenhuma aplicação prática do conteúdo vetores.

Gráfico 1. Resposta dos discentes ao questionário sobre aplicação de vetores

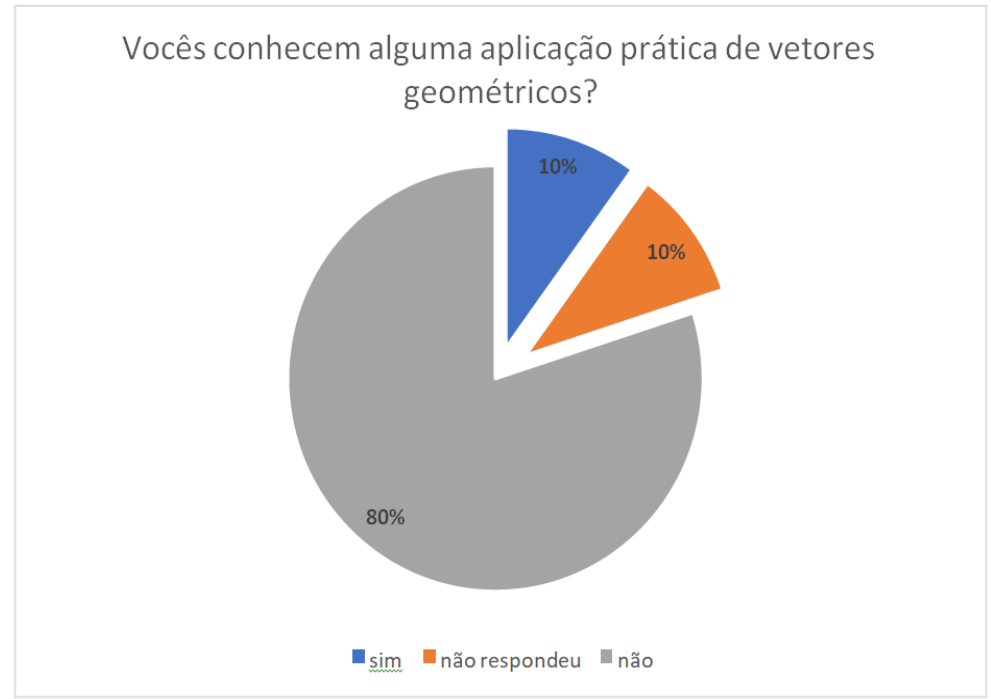

Fonte: Dados da pesquisa. 
Conforme o resultado apresentado a seguir no Gráfico 2, a maioria dos discentes do curso de licenciatura julgam importante o estudo dos vetores no curso de licenciatura, mesmo sem saberem justificar o porquê. Isso, certamente se deve ao fato de não conhecerem a aplicação prática dos mesmos, evidenciando que, por não conhecerem nenhuma aplicação dos vetores geométricos, não sabem relatar a importância de estudalos, mas apenas que é importante fazê-lo.

Gráfico 2. Reposta dos discentes ao questionário sobre a relevância do estudodos vetores no curso de licenciatura em matemática

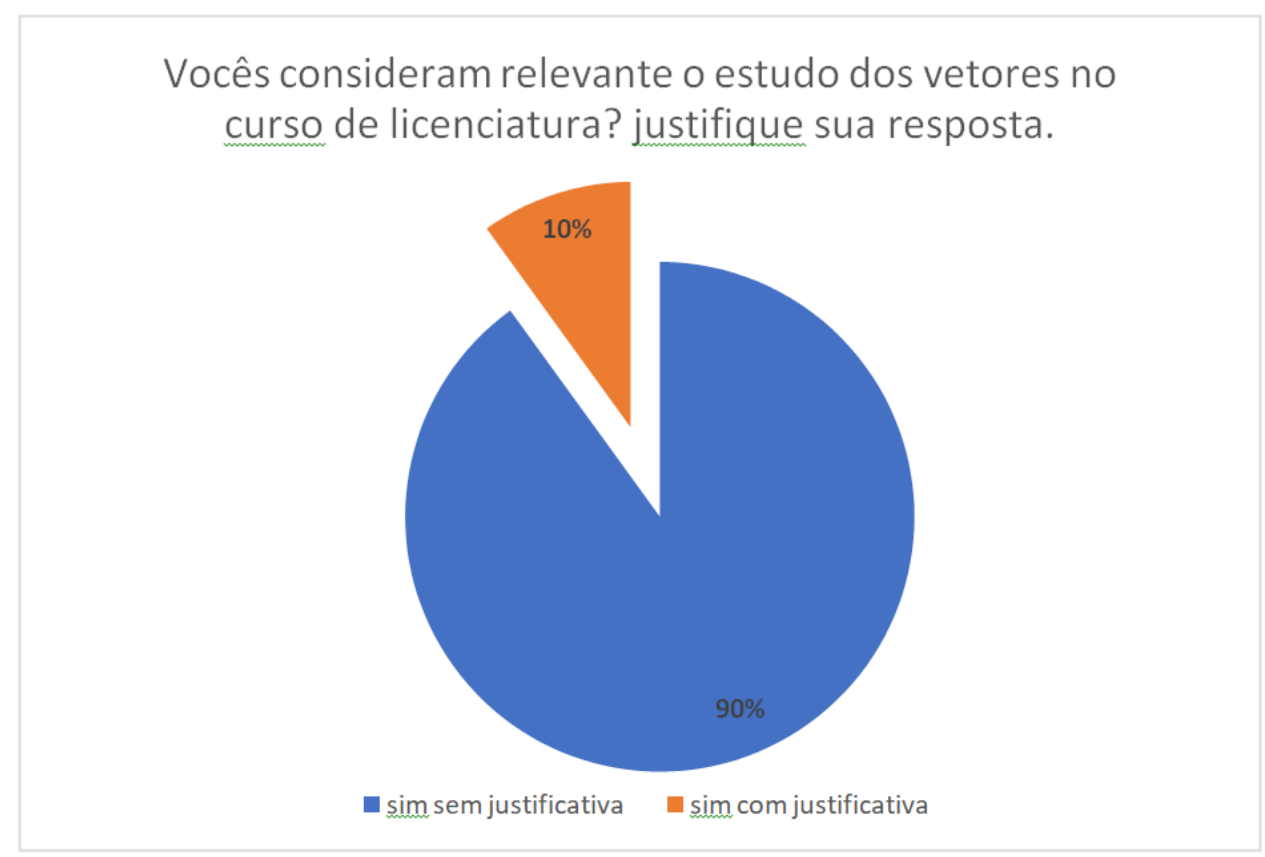

Fonte: Dados da pesquisa.

O Gráfico 3 mostram dos motivos pelos quais muitos dos discentes do curso de licenciatura em matemática não conseguem associar a teoria com a prática: na maioria das respostas, os alunos alegam que o professor que ministrou a disciplina não expôs a relação entre o conteúdo ministrado e outras áreas do conhecimento.

As respostas ao questionário representado no gráfico 3 , dadas por alguns discentes, divergem. $O$ aluno $X$ relatou que, durante as aulas de geometria analítica, não foi mostrada a aplicação prática de vetores, apenas a teoria. $\mathrm{O}$ aluno $\mathrm{Y}$ acrescentou que o professor da disciplina fez comentários sobre a aplicação de vetores na computação gráfica, mas não citou exemplos para mostrar tal aplicação. $O$ aluno $Z$ relatou em sua resposta que foi mostrada a aplicação de vetores, mas não descreveu essa aplicação. 


\section{ENSIN@UFMS 2021}

ISSN 2525-7056

As afirmações dos alunos diferem, pelo fato de alguns deles terem cursado a disciplina em questão, em turmas diferentes (alguns perderam a disciplina e tiveram que cursar novamente); assim, foram submetidos a metodologias de ensino que diferem uma da outra. No entanto, nota-se que a maioria dos professores que a ministram não apresentam a conexão dos conteúdos com outras áreas de conhecimento, assim como na formação desses professores, provavelmente isso não ocorreu.

Gráfico 3. Resposta dos discentes quando questionados se o professor da disciplinageometria analítica mostrou onde eles aplicariam vetores.

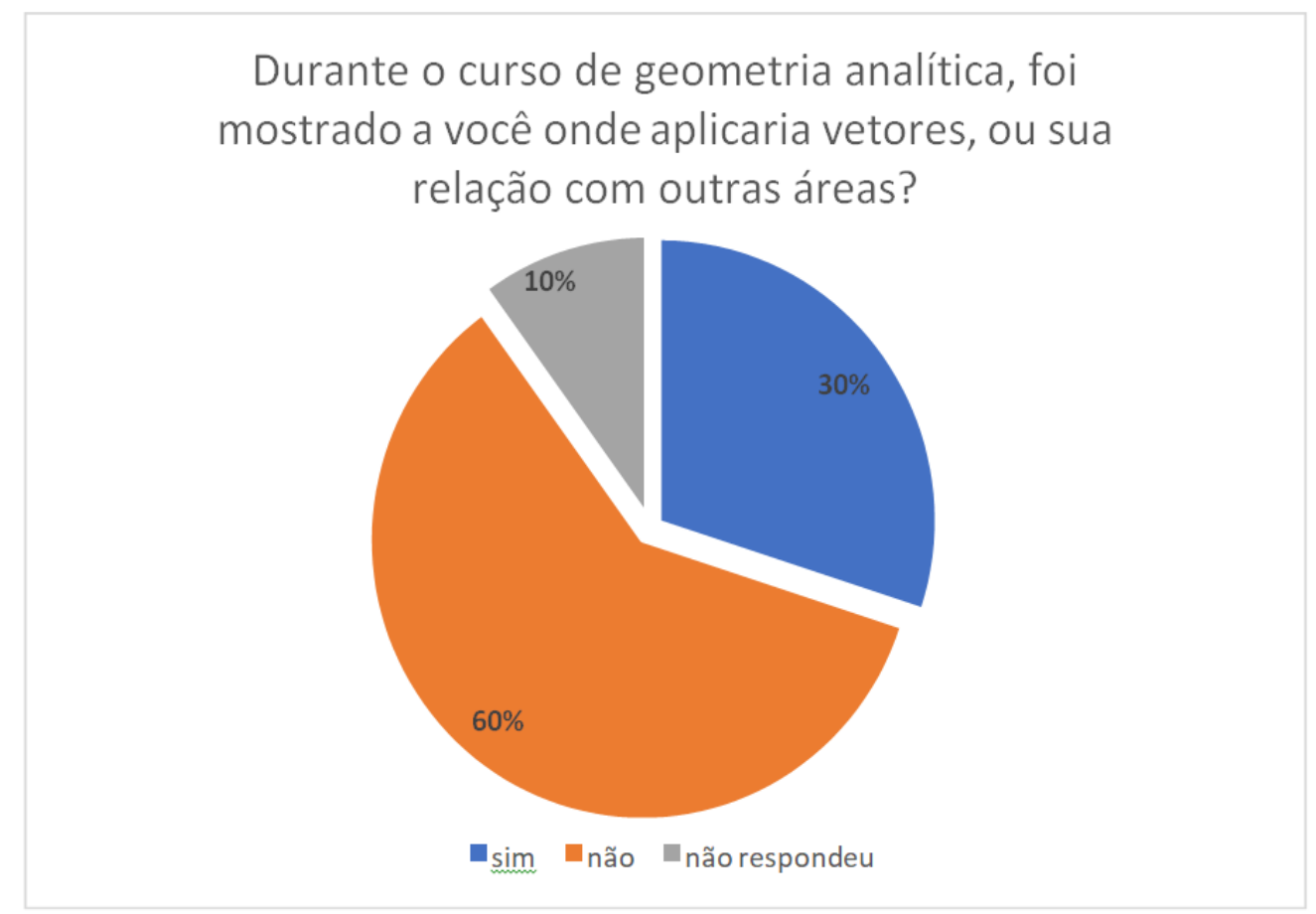

Fonte: Dados da pesquisa

Considerando o panorama mostrado, em que os alunos vivenciam a disciplina geometria analítica sem que haja a significação dos conteúdos através de aplicações em diversas áreas de conhecimento, a oficina proposta mostra uma forma de conectar o conteúdo de vetores à computação gráfica. Durante o desenvolvimento desse trabalho, ainda na primeira etapa descrita na metodologia, as questões voltadas a cálculos com vetores ajudaram o aluno a compreender o que acontece nos "bastidores" quando a bola está se movimentando pela tela.

A execução do presente trabalho foi concluída com um questionário com duas perguntas abertas (Apêndice D). A primeira, questiona os alunos sobre a eficácia deste trabalho para compreensão da aplicação dos vetores abordada nesse projeto; e a segunda, 
se os mesmos julgam mais prazeroso, satisfatório e eficaz o ensino da matemática quando seguido de aplicações, aquilo que se está aprendendo em sala de aula, passando do campo teórico para o prático, não tratando a matemática como uma ciência isolada. A conclusão que se tira após as respostas dos estudantes é que os objetivos da oficina proposta foram atingidos: os mesmos aprenderam uma aplicação do conteúdo de vetores e acharam interessante e prazerosa a metodologia utilizada.

Levando em consideração os dados levantados durante a realização da presente pesquisa, pode-se observar que o ensino da disciplina matemática tem maior aproveitamento quando associadas a teoria com a prática, e os conteúdos são trabalhados de forma contextualizada, mostrando assim a relação entre a matemática e outros campos do conhecimento.

A contextualização e a interdisciplinaridade devem estar presentes em novas discussões e abordagens metodológicas, inseridas em novas propostas de ensino levadas para a sala de aula, que tendem a proporcionar ao aluno a oportunidade de organizar seu conhecimento, estruturar dados e informações e desenvolver seu pensamento crítico. Os PCNs, reforçam que

Por outro lado, um conhecimento só é pleno se for mobilizado em situações diferentes daquelas que serviram para Ihe dar origem. Para que sejam transferíveis a novas situações e generalizados, os conhecimentos devem ser descontextualizados, para serem contextualizados novamente em outras situações. (BRASIL, 1997, p. 26).

Verifica-se, pois, que o ensino da matemática, quando munido de práticas e métodos que permitam o aluno relacioná-la com outras áreas, conhecer sua aplicação, e, por meio disso, atuar como sujeito ativo nesse processo, produzem resultados significativamente positivos.

\section{Considerações Finais}

Este trabalho relata o resultado de uma pesquisa desenvolvida com alunos do curso de Licenciatura em Matemática de uma instituição da Rede Federal de ensino, da cidade de São Raimundo Nonato-PI. A pesquisa em questão, abordou o conteúdo vetores de maneira a trabalhar um dos ramos da aplicação de tal componente matemático, de forma a dinamizar o ensino. Esse tipo de abordagem é uma alternativa interessante, baseada na interdisciplinaridade para o ensino da matemática. 
É relevante inovar a maneira de ensinar para que o aluno sinta-se motivado a aprender e busque construir seu conhecimento por meio de novas metodologias que conduzam a esse fim.

As etapas de desenvolvimento desse projeto, permitiram direcionar corretamente a realização das atividades propostas, e ajudaram a otimizar sua realização por meio das atividades que julgaram o conhecimento dos alunos sobre o conteúdo abordado, e aquelas que levaram os discentes a compreenderem qual a função das operações com vetores na programação usada para dar movimentos aos objetos dentro de um ambiente virtual.

Durante a execução das atividades, foi possível observar que os alunos apresentaram grande entusiasmo durante todo o desenvolvimento do projeto, visto que os mesmos sentiram-se envolvidos num processo empírico concreto, podendo assimilar melhor o conteúdo abordado no projeto em questão, associando a teoria com a prática.

Os resultados colhidos com a aplicação desse projeto nos permitem afirmar que métodos de ensino em que o aluno atua como sujeito ativo, no processo ensinoaprendizagem, colaboram positivamente com o aprendizado do mesmo.

Diante do exposto, levando em consideração a necessidade de se dinamizar o ensino da matemática, torna-se necessária a procura por métodos de ensino voltados ao enriquecimento das aulas por meios da aplicações práticas, para que o corpo discente entenda que a matemática está presente em tudo à sua volta, e para que possa percebêla no seu dia-a-dia. Cabe aqui lembrar, que esse trabalho trata da aplicação dos vetores de modo não aprofundado e traz uma introdução à lógica de programação usada em jogos de computadores.

Essa disquisição serve como base para pesquisas futuras sobre componentes matemáticos usados em programações usadas para dar ou auxiliar movimentos de seres em ambientes virtuais.

Para trabalhos futuros, a quem desejar pesquisar sobre tal tema, pode-se trabalhar o uso dos vetores em jogos de computadores com cálculos que produzam ações mais complexas, como por exemplo, a projeção ortogonal, ainda em duas dimensões, que pode ser usada em jogos de carrinhos de corrida para que, aqueles carros que não são controlados pelo jogador, não saiam da pista. Ou pode-se expandir a três dimensões com operações mais complexas, porém, com um leque maior de aplicações. 
Outros componentes matemáticos, como a trigonometria, por exemplo, também tem uma vasta aplicação na computação gráfica, e são uma rica fonte nesta linha de pesquisa.

\section{Referências}

BRASIL. Parâmetros Curriculares Nacionais. Disponível em:

http://portal.mec.gov.br/seb/arquivos/pdf/ciencian.pdf. Acesso em: 27 out. 2018.

DELGADO, J; FRENSEL, K; CRISSAFF, L. Geometria Analítica. Coleção Profmat. 1.ed. Rio de Janeiro: Editora SBM, 2013.

LAKATOS, E. M; MARCONI, M. A. Fundamentos de metodologia científica - 5. ed. São Paulo: Atlas 2003.

MARTINS, R. L. O ensino de vetores e a interdisciplinaridade. 79 f. Dissertação (Mestrado Profissional em Matemática em Rede Nacional - Profmat) - Universidade Estadual da Paraíba, Campina Grande, 2015. Disponível em:

http://tede.bc.uepb.edu.br/jspui/handle/tede/2382.

MASOLA, W. J, ALLEVATO, N. S. G. Dificuldades de aprendizagem matemática de alunos ingressantes na educação superior. Rev. Brasileira de Ensino Superior, Passo Fundo, V.5, n.1 (2019), p. 64-74, mar. 2016.

MENEZES, B. V. In: Encontro Científico Multidisciplinar, x.2, 2016, Aracajú.

Importância da aplicabilidade da matemática no cotidiano: Perspetiva do aluno Jovem e Adulto. Aracajú: (FAMA, 2016. p. 95-104, apud CONCEIÇÂO et al., 2015)

PRODANOV, C. C; FREITAS, E. C. Metodologia do Trabalho Científico: Métodos e Técnicas da pesquisa e do trabalho acadêmico. 2. ed - Novo Hamburgo: Feevale, 2013.

QUEIROZ, C; MOITA F. As tendências pedagógicas e seus pressupostos. Campina Grande; Natal: UEPB/UFRN, 2007.

REAS, C; FRY, B. Processing. Software de computação gráfica. Versão 3.3.5, 2001. Disponível em: https://www.filehorse.com/download-processing-64/31136/. Acesso em: 29 nov. 2021.

REIF, T. B. Programação de computadores: Uma proposta para o $9^{\circ}$ ano do Ensino Fundamental. 2017. 65f. Dissertação (Mestrado Profissional em Matemática em Rede Nacional - Profmat) - Universidade Federal de Juiz de Fora, Juiz de Fora, 2017.

Disponível em: https://sca.profmatsbm.org.br/sca_v2/get_tcc3.php?id=150390755. Acesso em 27 out. 2021.

RIGONNATO, M. Introdução ao Estudo dos Vetores e Aplicações no Ensino Médio. 60 fls. Dissertação (Mestrado Profissional em Matemática em Rede Nacional - Profmat) 
Universidade federal do Goiás-UFG, Goiânia, 2018. Disponível em: https://repositorio.ufjf.br/jspui/handle/ufjf/5845.

ROSA, M. S. Números complexos, Uma abordagem histórica para aquisição do conceito. 1998. 172 f. Dissertação (Mestrado em Educação Matemática) - Pontifícia Universidade Católica de São Paulo.

\author{
SANTOS, F. A. Aplicação de Vetores à Computação Gráfica: Um estudo de caso. \\ Dissertação (Mestrado Profissional em Matemática em Rede Nacional - Profmat) \\ Universidade Federal do Vale do São Francisco, Juazeiro - BA, 2017. Disponível: \\ https://univasf.edu.br/profmat,francisco_alves_dos_santos_turma_2017.pdf. \\ Acesso em: 14 out. 2021.
}

\title{
NOTAS
}

\section{IDENTIFICAÇÃO DO TEXTO}

O presente texto é uma adaptação de: APLICAÇÃO DE VETORES À COMPUTAÇÃO GRÁFICA: um estudo de caso, dissertação de Mestrado Profissional em Matemática em Rede Nacional (Profmat) apresentado na Universidade Federal do Vale do São Francisco (Univasf), Campus Juazeiro, BA, em 26/10/2018, elaborada sob orientação do Professor Dr. Alexandre Ramalho Silva.

\section{IDENTIFICAÇÃO DE AUTORIA}

Francisco Alves dos Santos. Mestre em matemática pela Universidade Federal do Vale do São Francisco (Univasf), Campus Juazeiro, Bahia. Professor EBTT do Instituto Federal do Piauí (IFPI), Campus Angical, PI, Brasil.

E-mail: fas@ifpi.edu.br

(iD) https://orcid.org/0000-0001-6386-1498

Alexandre Ramalho Silva. Doutor em nanociências e Materiais avançados pela Universidade Federal do ABC (UFABC). Professor da Universidade Federal do Vale do São Francisco (UNIVASF), Colegiado de Engenharia Mecânica, Juazeiro, BA, Brasil.

E-mail: alexrama.univasf@gmail.com

(D) https://orcid.org/0000-0002-0635-4171

\section{AGRADECIMENTOS}

Não se aplica.

\section{FINANCIAMENTO}

Não se aplica.

\section{CONSENTIMENTO DE USO DE IMAGEM}

Não se aplica.

\section{APROVAÇÃO DE COMITÊ DE ÉTICA EM PESQUISA \\ Não se aplica.}

\section{LICENÇA DE USO}

Autores mantêm os direitos autorais e concedem à revista ENSIN@ UFMS - ISSN 2525-7056 o direito de primeira publicação, com o trabalho simultaneamente licenciado sob a Licença Creative Commons Attribution (CC BY-NC-SA 4.0), que permite compartilhar e adaptar o trabalho, para fins não comerciais, reconhecendo a autoria do texto e publicação inicial neste periódico, desde que adotem a mesma licença, compartilhar igual. 


\section{EDITORES}

Patricia Helena Mirandola Garcia, Eugenia Brunilda Opazo Uribe, Gerson dos Santos Farias.

\section{HISTÓRICO}

Recebido em: 30/08/2021 - Aprovado em: 07/12/2021 - Publicado em: 15/12/2021.

\section{COMO CITAR}

SANTOS, F. A; SILVA, A. R. Aplicação de Vetores à Computação Gráfica: Um estudo de caso. Revista ENSIN@ UFMS, Três Lagoas, v. 2, número especial, p. 210-228. 2021. 